DOI: $10.12731 / 2070-7568-2021-10-2-70-83$

УДК 330

\title{
РОЛЬ ФИНАНСОВОЙ БЕЗОПАСНОСТИ В СИСТЕМЕ ЭКОНОМИЧЕСКОЙ БЕЗОПАСНОСТИ ХОЗЯЙСТВУЮЩЕГО СУБЪЕКТА
}

\author{
Чувашлова М.В., Васяева А.А., \\ Горловская Е.А., Починова М.А.
}

Экономическая безопасность России напрямую зависит от экономической безопасности каждого конкретного предприятия. Хозяйствуюшим субъектам в условиях непростого экономического положения страны приходится бороться с многочисленными внутренними и внешними угрозами, стараясь поддерживать стабильный уровень своего существования и развиваться одновременно. Одной из основных функииональных составляющих экономической безопасности является финансовая безопасность. Актуальность данной темы заключается в том, что на текущий момент имеет место недостаточная теоретическая проработанность понятийного аппарата в области финансовой безопасности, несовершенство теоретического инструментария ее оценки. Отсутствие адекватной оценки влечет за собой возникновение сложностей в управлении уровнем финансовой безопасности предприятия.

Цель: изучение понятия, сущчности и значения финансовой безопасности организации.

Метод или методология проведения работы: в статье использовались методы анализа, синтеза, обобщения, сравнения и другие.

Результаты: рассмотрены теоретические основы финансовой безопасности и финансовой устойчивости организации.

Ключевые слова: финансовая безопасность; финансовая устойчивость; предприятие; внешняя среда 


\section{THE ROLE OF FINANCIAL SECURITY \\ IN THE SYSTEM OF ECONOMIC SECURITY \\ OF AN ECONOMIC ENTITY}

\section{Chuvashlova M.V., Vasyaeva A.A., Gorlovskaya E.A., Pochinova M.A.}

The economic security of Russia directly depends on the economic security of each individual enterprise. Economic entities in the difficult economic situation of the country have to deal with numerous internal and external threats, trying to maintain a stable level of their existence and develop at the same time.

One of the main functional components of economic security is financial security. The relevance of this topic lies in the fact that at the moment there is insufficient theoretical elaboration of the conceptual apparatus in the field of financial security, imperfection of the theoretical tools for its assessment. The lack of an adequate assessment leads to difficulties in managing the level of financial security of the enterprise.

Purpose: the study of the concept, essence and meaning of the financial security of the organization.

Methodology: the article used methods of analysis, synthesis, generalization, comparison and others.

Results: the article considered the theoretical foundations of financial security and financial stability of the organization.

Keywords: financial security; financial stability; enterprise; external environment

Финансовая безопасность, будучи одной из основополагающих составляющих экономической безопасности организации, до сих пор не имеет устоявшегося и однозначного определения. Некоторые варианты интерпретации понятия «финансовая безопасность» представлены в таблице 1. 
Таблица 1.

Подходы авторов к пониманию сущности понятия «финансовая безопасность»

\begin{tabular}{|c|c|}
\hline Автор & $\begin{array}{c}\text { Предлагаемая трактовка понятия } \\
\text { «финансовая безопасность» }\end{array}$ \\
\hline И.О. Бланк [4] & $\begin{array}{l}\text { - количественно и качественно детерминированный уро- } \\
\text { вень финансового состояния предприятия, обеспечиваю- } \\
\text { щий стабильную защиту его приоритетных сбалансиро- } \\
\text { ванных финансовых интересов от идентифицированных } \\
\text { реальных и потенциальных угроз внутреннего и внешнего } \\
\text { характера, параметры которого определяются на основе } \\
\text { его финансовой философии и создают необходимые пред- } \\
\text { посылки финансовой поддержки устойчивого развития в } \\
\text { текущем и перспективном периодах }\end{array}$ \\
\hline К.С. Горячева [8] & $\begin{array}{l}\text { - финансовое состояние предприятия, характеризую- } \\
\text { щееся сбалансированностью и качеством финансовых } \\
\text { инструментов, технологий и услуг, устойчивостью к } \\
\text { угрозам, способностью финансовой системы предпри- } \\
\text { ятия обеспечивать реализацию собственных финансовых } \\
\text { интересов, миссии и задач достаточными объемами фи- } \\
\text { нансовых ресурсов, а также обеспечивать эффективное и } \\
\text { устойчивое развитие его финансовой системы }\end{array}$ \\
\hline $\begin{array}{l}\text { Т.Б. Кузенко, } \\
\text { В.В. Прохорова } \\
{[9,19]}\end{array}$ & $\begin{array}{l}\text { - наиболее эффективное использование информацион- } \\
\text { ных, финансовых показателей, ликвидности и платеже- } \\
\text { способности, рентабельности капитала, которые находят- } \\
\text { ся в пределах своих граничных значений }\end{array}$ \\
\hline $\begin{array}{l}\text { 3.А. Круш, } \\
\text { А.В. Татаринская [9] }\end{array}$ & $\begin{array}{l}\text { - финансовое состояние предприятия, характеризующееся } \\
\text { определенным интервалом критических значений, при ко- } \\
\text { торых обеспечивается защита от негативного воздействия } \\
\text { опасностей и угроз, гарантирующей хозяйствующему субъ- } \\
\text { екту конкурентоспособность и самодостаточность, а также } \\
\text { обеспечение устойчивого функционирования и роста в кра- } \\
\text { ткосрочном и долгосрочном периоде }\end{array}$ \\
\hline А.А. Эфипанов [13] & $\begin{array}{l}\text { - состояние предприятия, позволяющее обеспечить фи- } \\
\text { нансовое равновесие, стабильность, платежеспособность } \\
\text { и ликвидность в долгосрочном периоде, достаточную } \\
\text { финансовую независимость, потребности в финансовых } \\
\text { ресурсах для устойчивого расширенного воспроизвод- } \\
\text { ства, достаточную гибкость при принятии финансовых } \\
\text { решений }\end{array}$ \\
\hline $\begin{array}{l}\text { О.А. Кириченко, } \\
\text { С.М. Лаптев, } \\
\text { П.Я. Прыгунов, } \\
\text { О.И. Захаров [13] }\end{array}$ & $\begin{array}{l}\text { - состояние наиболее эффективного использования } \\
\text { корпоративных ресурсов предприятия, выраженное в } \\
\text { лучших значениях финансовых показателей прибыли и } \\
\text { рентабельности бизнеса, качества управления, исполь- } \\
\text { зования основных и оборотных средств предприятия, } \\
\text { структуры его капитала, нормы дивидендных выплат по } \\
\text { ценным бумагам, курсовой стоимости его ценных бумаг } \\
\text { как синтетического индикатора текущего финансово-хо- } \\
\text { зяйственного состояния предприятия и перспектив техно- } \\
\text { логического и финансового развития }\end{array}$ \\
\hline
\end{tabular}


Окончание табл. 1.

\begin{tabular}{|c|c|}
\hline К.О. Багаева [24] & $\begin{array}{l}\text { - готовность и способность хозяйствующего субъекта эффек- } \\
\text { тивно обеспечивать функцинирование процесса распределе- } \\
\text { ния и перераспределения ограниченных денежных и финан- } \\
\text { совых ресурсов при наличии внешних и внутренних угроз }\end{array}$ \\
\hline $\begin{array}{l}\text { Н.А. Казакова, } \\
\text { А.Н. Иванова [13] }\end{array}$ & $\begin{array}{l}\text { - состояние финансовой среды предприятия, при котором } \\
\text { оно имеет возможность эффективно функционировать в } \\
\text { соответствии с целями, определяемыми собственниками } \\
\text { бизнеса, оперативно и адекватно реагировать на изме- } \\
\text { нения, происходящие во внешней и внутренней среде, и } \\
\text { адаптироваться к ним, не теряя автономности и без сни- } \\
\text { жения результативности }\end{array}$ \\
\hline П.А. Никифоров [17] & $\begin{array}{l}\text { - результат взвешенного и оптимального подхода пред- } \\
\text { приятия к использованию финансовых ресурсов и управ- } \\
\text { лению ими, четкого их контроля, оперативного реагиро- } \\
\text { вания на любые внутренние или внешние угрозы для их } \\
\text { минимизации или предотвращения без ущерба для общей } \\
\text { деятельности }\end{array}$ \\
\hline Л.Г. Мельник [9] & $\begin{array}{l}\text { - достижение наиболее эффективного использования кор- } \\
\text { поративных ресурсов }\end{array}$ \\
\hline Р.С. Папехин [20] & $\begin{array}{l}\text { - предельное состояние финансовой устойчивости, в ко- } \\
\text { тором должно находиться предприятие для реализации } \\
\text { своей стратегии, характеризующееся его способностью } \\
\text { противостоять внутренним и внешним угрозам } \\
\text { - способность предприятия самостоятельно разрабаты- } \\
\text { вать и проводить финансовую стратегию в соответствии } \\
\text { с целями общей корпоративной стратегии в условиях } \\
\text { неопределенной и конкурентной среды, главным ус- } \\
\text { ловием которой является способность противостоять } \\
\text { существующим и возникающим опасностям и угрозам, } \\
\text { способным причинить предприятию финансовый ущерб } \\
\text { или нежелательно изменить структуру его капитала или } \\
\text { принудительно ликвидировать предприятие }\end{array}$ \\
\hline Д.В. Ермолаев [10] & $\begin{array}{l}\text { - достижение наиболее эффективного использования } \\
\text { корпоративных ресурсов с точки зрения высокого уровня } \\
\text { платежеспособности предприятия и ликвидности, макси- } \\
\text { мизации прибыли и уровня рентабельности }\end{array}$ \\
\hline Н.И. Реверчук [21] & $\begin{array}{l}\text { - защита предприятия от возможных финансовых потерь } \\
\text { и банкротства, достижение наиболее эффективного ис- } \\
\text { пользования корпоративных ресурсов }\end{array}$ \\
\hline О.Н. Овечкина [18] & $\begin{array}{l}\text { - способность предприятия обеспечивать устойчивость } \\
\text { состояния и поступательность развития в условиях по- } \\
\text { стоянно изменяющейся внутренней и внешней среды, } \\
\text { сохранять иммунитет к действию угроз }\end{array}$ \\
\hline $\begin{array}{l}\text { О. Н. Бадаева, } \\
\text { Е.В. Цупко [1] }\end{array}$ & $\begin{array}{l}\text { - финансовое состояние предприятия, характеризующе- } \\
\text { еся его способностью и возможностью противостоять } \\
\text { существующим и возникающим угрозам его финансовым } \\
\text { интересам }\end{array}$ \\
\hline
\end{tabular}


Анализируя различные точки зрения отечественных авторов относительно сущности категории «финансовая безопасность» организации, можно выделить два основных подхода [15].

Первый сконцентрирован на понятии угрозы как совокупности условий и факторов, представляющих опасность для жизненно важных интересов хозяйствующего субъекта. С этой позиции, финансовая безопасность сводится к защите от внешних и внутренних угроз.

В основе второго подхода - необходимость достижения целей хозяйственной деятельности организации, и, исходя из этого, сущность финансовой безопасности понимается как способность и возможность предприятия нормально функционировать [2].

Помимо этого, финансовая безопасность может рассматриваться как состояние организации, как условие нормального функционирования, как процесс защиты и как обеспечение развития $[3,6,11$, $14,16,23,25,28,29]$.

Общая вышесказанное, можно определить термин «финансовая безопасность» предприятия как состояние финансовой системы организации, которое способствует обеспечению наиболее эффективного использования ресурсов организации, и одновременно противодействует угрозам, или ослабляет их воздействие, способствуя достижению целей хозяйствующего субъекта.

Главная цель финансовой безопасности организации - это обеспечение ее устойчивого и эффективного развития в долгосрочной перспективе при минимизации возможных угроз. Их идентификация - необходимое условие формирования действенной системы финансовой безопасности. При этом под угрозами понимают совокупность условий и факторов, способствующих возможности нанесения ущерба интересам предприятия в сфере финансовых отношений.

Важно отметить, что без обеспечения финансовой безопасности предприятие не может эффективно функционировать, даже существовать, что определяет высокую степень значимости данной функциональной составляющей экономической безопасности предприятия в целом. 
В отечественной литературе можно встретить точку зрения относительно тождественности понятий «финансовая безопасность» и «экономическая безопасность» $[3,4,7,6]$.

Так, согласно одному из распространенных определений сущности экономической безопасности, ее можно рассматривать как состояние наиболее эффективного использования ресурсов организации для предотвращения угроз и обеспечения стабильного функционирования, что тесно коррелирует с финансовой безопасностью. Однако более обоснованно рассматривать последнюю как один из элементов системы экономической безопасности организации [7]. При этом финансовый компонент имеет настолько важное значение, что это становится еще одним поводом отождествлять финансовую безопасность с экономической, упуская из виду остальные составляющие $[6,7,12]$.

Таблица 2.

Подходы российских авторов к пониманию сущности понятия «финансовая устойчивость» организации

\begin{tabular}{|l|l|}
\hline \multicolumn{1}{|c|}{ Автор } & Содержание определения «финансовая устойчивость» \\
\hline В.В. Бочаров [5] & $\begin{array}{l}\text { состояние денежных ресурсов, обеспечивающее развитие } \\
\text { предприятия преимущественно за счет собственных средств } \\
\text { при сохранении платежеспособности и кредитоспособности } \\
\text { и минимальном уровне предпринимательского риска }\end{array}$ \\
\hline Г.В. Савицкая [22] & $\begin{array}{l}\text { способность предприятия функционировать и развиваться, } \\
\text { сохранять равновесие своих активов и пассивов в изменя- } \\
\text { ющейся внутренней и внешней среде, гарантирующее ... } \\
\text { постоянную платежеспособность и инвестиционную при- } \\
\text { влекательность в границах допустимого уровня риска }\end{array}$ \\
\hline $\begin{array}{l}\text { А.Д. Шеремет и } \\
\text { др. [27] }\end{array}$ & $\begin{array}{l}\text { способность предприятия поддерживать свое суще- } \\
\text { ствование и бесперебойную работу, благодаря наличию } \\
\text { определенных свободных средств и сбалансированности } \\
\text { финансовых потоков }\end{array}$ \\
\hline $\begin{array}{l}\text { А.В. Цветых, } \\
\text { К.Ю. Лобков [26] }\end{array}$ & $\begin{array}{l}\text { способность предприятия восстанавливать (сохранять) } \\
\text { состояние сбалансированности, пропорциональности } \\
\text { и эффективности финансово-экономических процессов } \\
\text { функцинирования, сохраняя финансовые предпосылки } \\
\text { для развития в меняющейся внутренней и внешней среде }\end{array}$ \\
\hline
\end{tabular}

Говоря о сущности финансовой безопасности организации, важно разграничить ее с понятием финансовой устойчивости. Несмотря на то, что некоторые ученые и практики ставят знак равенства между 
данными экономическими категориями, в отечественной литературе финансовая устойчивость преимущественно рассматривается как элемент системы финансовой безопасности, условие или следствие ее достижения и сохранения.

Понятие «финансовая устойчивость» не имеет однозначного толкования, и некоторые его варианты представлены в таблице 2.

Финансовая устойчивость подразумевает такое состояние финансовых ресурсов организации, которое может обеспечить бесперебойный расширенный процесс производства и реализации продукции на основе роста прибыли. И если рассматривать финансовую безопасность как состояние финансовой системы организации, то финансовая устойчивость будет одним из ее элементов. С другой стороны, если финансовая безопасность - это способность предприятия противостоять угрозам финансовым интересам компании [18], то финансовая устойчивость может рассматриваться как следствие финансовой безопасности.

\section{Вывод}

В контексте обеспечения экономической безопасности в целом целесообразно рассматривать финансовую безопасность предприятия как средство формирования и реализации целей его финансово-хозяйственной деятельности.

Реализация стратегии компании зависит от управления ее денежными потоками, что определяет основополагающую роль финансового компонента в системе экономической безопасности фирмы.

\section{Список литературы}

1. Бадаева О.Н. Оценка финансовой безопасности малых и средних предприятии / О. Н. Бадаева, Е. В. Цупко // Российское предпринимательство. 2013. № 4 (236). С. 71-83.

2. Безопасность предпринимательской деятельности: практическое пособие / А. П. Судоплатов, С. В. Лекарев. М.: Олма-Пресс, 2001. $382 \mathrm{c}$. 
3. Безуглая Н.С. Механизм создания адаптивной системы экономической безопасности предприятия на основе принципов минимизации рисков // Управление экономическими системами. 2012. N 3 (39). C. 11.

4. Бланк И.А. Управление финансовой безопасностью предприятия. М.: Эльга, 2009. 776 с.

5. Бочаров В.В. Финансовый анализ : краткий курс. 2-е изд., доп и перераб.. СПб.: Питер, 2009. 95 с.

6. Бурцев В.В. Факторы финансовой безопасности России // Менеджмент в России и за рубежом. 2001. № 1. С. 55-69.

7. Гончаренко Л.П. Процесс обеспечения экономической безопасности предприятия // Справочник экономиста. 2004. № 12. С. 14-18.

8. Горячева К.С. Информационно-аналитическое обеспечение финансовой безопасности предприятия // Актуальные проблемы экономики. 2003. № 9. С. 16-21.

9. Еремеева С.С. Финансовая безопасность предприятия как основной критерий его экономической безопасности // Финансы и учетная политика. 2019. № 5 (9). С. 17-21.

10. Ермолаев Д.В. Составляющие экономической безопасности предприятия // Ученые записки Орловского государственного университета. Серия: Гуманитарные и социальные науки. 2012. № 4 (48). С. 15-17.

11. Загорельская Т.Ю. Финансовая безопасность предприятия как объект управления // Научные труды ДонНТУ. Серия Экономика. 2006. Выпуск 103-4. С. 215-218.

12. Казакова Н.А. Концепция контроллинга экономической безопасности региона // Фундаментальные исследования. 2015. № 11-6. C. 1180-1183.

13. Казакова Н. А. Финансовая безопасность компании: аналитический аспект / Н.А. Казакова, А.Н. Иванова // Экономический анализ: теория и практика. 2016. № 10(457). С. 93-105.

14. Коробов В.В. Финансовая безопасность в системе государственного финансового контроля: дис. ... канд. экон. наук. Иваново, 2010. $133 \mathrm{c}$. 
15. Куликова Л.А. Особенности финансовой составляющей экономической безопасности предприятия / Л.А. Куликова, В.В. Ушаков // Экономика и бизнес: теория и практика. 2020. № 8(66). С. 86-89.

16. Национальная экономика России: потенциалы, комплексы, экономическая безопасность / под общ. ред. В. И. Лисова. М.: Экономика, 2000. 447 c.

17.Никифоров П.А. Сущность и значение финансовой безопасности страховой компании // Финансы Украины. 2006. № 5. С. 86-90.

18. Овечкина О.Н. Понятие и методика оценки финансовой безопасности предприятия // Вопросы экономики и права. 2013. N 57. С. 87-92.

19. Орехова Е.В. Управление угрозами финансовой безопасности предприятия // Экономика промышленности. 2013. № 1-2 (62). С. 76-83.

20. Папехин Р.С. Факторы финансовой устойчивости и безопасности предприятия: автореф. дис. ... канд. экон. наук. Волгоград, 2007. 21 с.

21. Реверчук Н.И. Влияние маркетинговой безопасности на деловую репутацию предприятия / Н.И. Реверчук, Е.С. Дзямулич // Universum: экономика и юриспруденция. 2014. № 5(6). С. 4.

22. Савицкая Г.В. Анализ хозяйственной деятельности предприятия: учебник. М. : ИНФРА-М, 2017. 378 с.

23. Сорокина О.Н. Содержание финансовой безопасности предприятия // Российское предпринимательство. 2012. № 14 (112). С. 74-80.

24. Стадолина Е.А. Стратегия финансовой безопасности на предприятии // Молодой ученый. 2019. № 2 (240). С. 274-275.

25. Финансовая безопасность предприятий и банковских учреждений / под ред. А.А. Епифанова. Сумы: УАБД НБУ, 2014. 295 с.

26. Цветцых А.В. Финансовая устойчивость предприятия: сущность и оценка / А.В. Цветцых, К.Ю. Лобков // Азимут научных исследований: экономика и управление. 2021. Т. 10, № 1 (34). С. 371-374.

27. Шеремет А.Д. Методика финансового анализа деятельности коммерческих организаций / А.Д. Шеремет, Е.В. Негашев. М.: Инфра-М, 2003. 237 c.

28. Экономическая безопасность России: общий курс: учебник / под ред. В.К. Сенчагова. 2-е изд. М.: Дело, 2005. 896 с. 
29. Экономическая и финансовая безопасность: учебник / под ред. Е. А. Олейникова. М.: Экзамен, 2004. 768 с.

\section{References}

1. Badaeva O.N., Tsupko E.V. Otsenka finansovoy bezopasnosti malykh i srednikh predpriyatiy [Assessment of financial security of small and medium-sized enterprises]. Rossiyskoe predprinimatel'stvo, 2013, no. 4 (236), pp. 71-83.

2. Sudoplatov A.P., Lekarev S.V. Bezopasnost'predprinimatel'skoj dejatel'nosti: prakticheskoe posobie [Safety of entrepreneurial activity: a practical guide]. M.: Olma-Press, 2001, 382 p.

3. Bezuglaya N.S. Mekhanizm sozdaniya adaptivnoy sistemy ekonomicheskoy bezopasnosti predpriyatiya na osnove printsipov minimizatsii riskov [The mechanism for creating an adaptive system of economic security of an enterprise based on the principles of risk minimization]. Upravlenie ekonomicheskimi sistemami, 2012, no. 3 (39), p. 11.

4. Blank I.A. Upravlenie finansovoj bezopasnost'ju predprijatija [Financial security management of the enterprise]. M.: Jel'ga, 2009, 776 p.

5. Bocharov V.V. Finansovyj analiz: kratkij kurs [Financial analysis: a short course]. SPb.: Piter, 2009, 95 p.

6. Burcev V.V. Faktory finansovoj bezopasnosti Rossii [Factors of financial security of Russia]. Menedzhment v Rossii i za rubezhom, 2001, no. 1, pp. 55-69.

7. Goncharenko L.P. Process obespechenija jekonomicheskoj bezopasnosti predprijatija [The process of ensuring the economic security of an enterprise]. Spravochnik jekonomista, 2004, no. 12, pp. 14-18.

8. Gorjacheva K.S. Informacionno-analiticheskoe obespechenie finansovoj bezopasnosti predprijatija [Information and analytical support of the financial security of the enterprise]. Aktual'nye problemy jekonomiki, 2003, no. 9, pp. 16-21.

9. Eremeeva S.S. Finansovaja bezopasnost' predprijatija kak osnovnoj kriterij ego jekonomicheskoj bezopasnosti [Financial security of an enterprise as the main criterion of its economic security]. Finansy $i$ uchetnaja politika, 2019, no. 5 (9), pp. 17-21. 
10. Ermolaev D.V. Sostavljajushhie jekonomicheskoj bezopasnosti predprijatija [Components of the economic security of the enterprise]. Uchenye zapiski Orlovskogo gosudarstvennogo universiteta. Serija: Gumanitarnye i social'nye nauki, 2012, no. 4 (48), pp. 15-17.

11. Zagorel'skaja T.Ju. Finansovaja bezopasnost' predprijatija kak ob\#ekt upravlenija [Financial security of the enterprise as an object of management]. Nauchnye trudy DonNTU. Serija Jekonomika, 2006, issue 103-4, pp. 215-218

12.Kazakova N.A. Koncepcija kontrollinga jekonomicheskoj bezopasnosti regiona [The concept of controlling the economic security of the region]. Fundamental'nye issledovanija, 2015, no. 11-6, pp. 11801183.

13. Kazakova N.A., Ivanova A.N. Finansovaja bezopasnost' kompanii: analiticheskij aspekt [Financial security of the company: analytical aspect]. Jekonomicheskij analiz: teorija i praktika, 2016, no. 10(457), pp. 93-105.

14. Korobov V.V. Finansovaja bezopasnost'v sisteme gosudarstvennogo finansovogo kontrolja [Financial security in the system of state financial control]. Ivanovo, 2010, $133 \mathrm{p}$.

15. Kulikova L.A., Ushakov V.V. Osobennosti finansovoj sostavljajushhej jekonomicheskoj bezopasnosti predprijatija [Features of the financial component of the economic security of the enterprise]. Jekonomika $i$ biznes: teorija i praktika, 2020, № 8(66), pp. 86-89.

16. Nacional'naja jekonomika Rossii: potencialy, kompleksy, jekonomicheskaja bezopasnost' [The national economy of Russia: potentials, complexes, economic security]. ed. V. I. Lisov. M.: Jekonomika, 2000, 447 p.

17. Nikiforov P.A. Sushhnost' i znachenie finansovoj bezopasnosti strahovoj kompanii [The essence and significance of the financial security of an insurance company]. Finansy Ukrainy, 2006, no. 5, pp. 86-90.

18. Ovechkina O.N. Ponyatie i metodika otsenki finansovoy bezopasnosti predpriyatiya [Concept and methodology for assessing the financial security of an enterprise]. Voprosy ekonomiki i prava, 2013, no. 57, pp. 87-92. 
19. Orehova E.V. Upravlenie ugrozami finansovoj bezopasnosti predprijatija [Management of threats to the financial security of an enterprise]. Jekonomika promyshlennosti, 2013, no. 1-2 (62), pp. 76-83.

20.Papekhin R.S. Faktory finansovoy ustoychivosti i bezopasnosti predpriyatiya [Factors of financial stability and security of the enterprise]. Volgograd, 2007. $21 \mathrm{p}$.

21. Reverchuk N.I., Dzjamulich E.S. Vlijanie marketingovoj bezopasnosti na delovuju reputaciju predprijatija [The influence of marketing security on the business reputation of an enterprise]. Universum: jekonomika $i$ jurisprudencija, 2014, no. 5(6), p. 4.

22. Savickaja G.V. Analiz hozjajstvennoj dejatel'nosti predprijatija: uchebnik [Analysis of the economic activity of the enterprise: textbook]. M.: INFRA-M., 2017, 378 p.

23. Sorokina O.N. Soderzhanie finansovoj bezopasnosti predprijatija [Content of the financial security of the enterprise]. Rossijskoe predprinimatel'stvo, 2012, no. 14 (112), pp. 74-80.

24. Stadolina E.A. Strategija finansovoj bezopasnosti na predprijatii [Financial security strategy at the enterprise]. Molodoj uchenyj, 2019, no. 2 (240), pp. 274-275.

25. Finansovaja bezopasnost'predprijatij i bankovskih uchrezhdenij [Financial security of enterprises and banking institutions]. ed. A.A. Epifanov. Sumy: UABD NBU, 2014, 295 p.

26. Cvetcyh A.V., Lobkov K.Ju. Finansovaja ustojchivost' predprijatija: sushhnost' i ocenka [Financial stability of the enterprise: essence and assessment]. Azimut nauchnyh issledovanij: jekonomika i upravlenie, 2021, vol. 10, no. 1 (34), pp. 371-374.

27. Sheremet A.D., Negashev E.V. Metodika finansovogo analiza dejatel'nosti kommercheskih organizacij [Methodology of financial analysis of the activities of commercial organizations]. M.: Infra-M, 2003, 237 p.

28. Jekonomicheskaja bezopasnost'Rossii: obshhij kurs: uchebnik [Economic security of Russia: general course: textbook]. ed. V.K. Senchagov. M.: Delo, 2005, 896 p.

29. Jekonomicheskaja i finansovaja bezopasnost': uchebnik [Economic and financial security: textbook]. ed. E. A. Olejnikov. M.: Jekzamen, 2004, 768 p. 


\section{ДАННЫЕ ОБ АВТОРАХ}

Чувашлова Марина Владимировна, профессор, доктор экономических наук

Ульяновский государственный университет

ул. Льва Толстого, 42, г. Ульяновск, 432970, Российская Федеращия

chuvashlova@mail.ru

Васяева Анна Александровна, студент 2 курса магистратуры бизнес-факультета

Ульяновский государственньй университет

ул. Льва Толстого, 42, г. Ульяновск, 432970, Российская Федеращия

anna.alex.vas@mail.ru

Горловская Екатерина Алексеевна, студент 5 курса факультета трансферных специальностей

Ульяновский государственный университет

ул. Льва Толстого, 42, г. Ульяновск, 432970, Российская Федерация

katrin.denev@bk.ru

Починова Мария Александровна, студент 5 курса факультета трансферных специальностей

Ульяновский государственный университет

ул. Льва Толстого, 42, г. Ульяновск, 432970, Российская Федераичия

masapocinova@gmail.com

\section{DATA ABOUT THE AUTHORS}

Chuvashlova Marina V., Professor, Doctor of Economic Sciences Ulyanovsk State University 42, Lev Tolstoy Str., Ulyanovsk, 432970, Russian Federation chuvashlova@mail.ru 
Vasyaeva Anna A., 2nd year master's student of the Business Faculty Ulyanovsk State University 42, Lev Tolstoy Str., Ulyanovsk, 432970, Russian Federation anna.alex.vas@mail.ru

Gorlovskaya Ekaterina A., 5th year student of the Faculty of Transfer Specialties

Ulyanovsk State University

42, Lev Tolstoy Str., Ulyanovsk, 432970, Russian Federation katrin.denev@bk.ru

Pochinova Maria A., 5th year student of the Faculty of Transfer Specialties

Ulyanovsk State University

42, Lev Tolstoy Str., Ulyanovsk, 432970, Russian Federation masapocinova@gmail.com 